\title{
Simultaneous determination of aspartame, acesulfame-K, saccharin, citric acid and sodium benzoate in various food products using HPLC-CAD-UV/DAD
}

\author{
Małgorzata Grembecka • Piotr Baran • \\ Agata Błażewicz $\cdot$ Zbigniew Fijałek • Piotr Szefer
}

Received: 30 July 2013 / Revised: 26 September 2013 / Accepted: 30 September 2013 / Published online: 18 October 2013

(C) The Author(s) 2013. This article is published with open access at Springerlink.com

\begin{abstract}
A newly developed method for simultaneous determination of aspartame, acesulfame-K, saccharin, citric acid and sodium benzoate in various diet supplements and non-alcoholic beverages in a single run is presented. The analytes were analysed by high-performance liquid chromatography coupled to a charged aerosol (Corona CAD) and ultraviolet-diode array detectors simultaneously connected in series. Mass spectrometer MicrOTOF-QII from Bruker Daltonik (Bremen, Germany) was used to obtain the mass spectra for peak identifications. The method was validated using a Thermo Hypersil Gold-C18 column packed with $5 \mu \mathrm{m}$ shell particles $(150 \times 4.6 \mathrm{~mm})$ and methanol-water with $0.05 \%$ TFA gradient mobile phase at a flow rate of $0.80 \mathrm{~mL} / \mathrm{min}$. The elaborated method was validated for linearity, precision and accuracy. The analytical results obtained in the validation study were highly satisfying; the recoveries for the analytes studied ranged between 98.1 and $101 \%$ and the precision values from 0.11 to $1.73 \%$. By these procedures, the three sweeteners (aspartame, acesulfame-K and saccharin), citric acid and sodium benzoate could be well separated and quantitatively determined in varied food products. Hundred millilitres of soft drinks contained on average $5.50 \mathrm{mg}$ of aspartame, $6.38 \mathrm{mg}$ of saccharin, $8.94 \mathrm{mg}$ of acesulfame-K, $9.05 \mathrm{mg}$ of sodium benzoate and $111 \mathrm{mg}$ of citric acid. Citric acid was the most abundant additive in all the samples analysed except for table sweeteners, and its highest concentration
\end{abstract}

\footnotetext{
M. Grembecka $(\square) \cdot$ P. Szefer

Department of Food Sciences, Medical University of Gdansk, Al. Gen. J. Hallera 107, 80-416 Gdańsk, Poland

e-mail: mgrembecka@gumed.edu.pl

P. Baran · A. Błażewicz · Z. Fijałek

Department of Pharmaceutical Chemistry, National Medicines

Institute, ul. Chełmska 30/34, 00-725 Warsaw, Poland
}

was determined in diet supplements, i.e. $347 \mathrm{mg} / \mathrm{g}$. The percentage of adequate daily intake realisation in case of all additives is lower than $10 \%$, except for sodium benzoate in isotonic drinks $(10.1 \%)$.

Keywords Food additives - HPLC C Corona CAD . UV/DAD $\cdot$ ESI-TOF-MS

\section{Introduction}

According to Community legislation food additive is defined as "any substance not normally consumed as a food in itself and not normally used as a characteristic ingredient of food whether or not it has nutritive value, the intentional addition of which to food for a technological purpose in the manufacture, processing, preparation, treatment, packaging, transport or storage of such food results, or may be reasonably expected to result, in it or its by-products becoming directly or indirectly a component of such foods" [1]. Food additives may only be authorised if there is a technological need for their use; they do not mislead the consumer and they present no health hazard to the consumer. The Community legislation on food additives is based on the principle that only those additives that are explicitly authorised may be used. Most food additives may only be used in limited quantities in certain foodstuffs. If no quantitative limits are foreseen for the use of a food additive, it must be used according to good manufacturing practice, i.e. only as much as necessary to achieve the desired technological effect.

Health effects and safety aspects of food are important issues for today's consumers, and some people are concerned about safety of certain food additives such as sweeteners or preservatives [2]. One of the current trends in the 
food industry is to mix several kinds of additives in order to obtain synergistic effects between them as with sweeteners and preservatives [3]. Sweeteners are reckoned as high-consumption food additives as they are used in large amounts in products such as soft drinks and tabletop sweeteners. The soft drink industry is one of the largest in the world, with revenue from sales of carbonated soft drinks totalling billions of dollars annually. Their critical components food additives, i.e. preservatives and sweeteners must be identified on the beverage's label.

The use of food additives is regulated in most countries; therefore, analytical methods that simultaneously determine these substances are necessary for maintaining food quality and promoting food safety. The most popular choice for the determination of additives is high-performance liquid chromatography (HPLC) [4-9], but also other analytical methods have been applied in their analysis [1013]. However, food additives analyses using HPLC Corona CAD are scarce up to date [14].

The Corona, charged aerosol detector (CAD), is a new type of universal detector that was introduced by Dixon and Peterson in 2002 [15]. CAD has been reported to offer potential improvements over other universal detectors, i.e. lower detection limit and wider dynamic range [16-19]. Charged aerosol detection is a unique technique in which the HPLC column eluent is first nebulised with nitrogen, and the droplets are dried, producing analyte particles. A secondary stream of nitrogen becomes positively charged as it passes a high-voltage corona wire. This charge transfers diffusionally to the opposing stream of analyte particles. The amount of charge acquired is directly proportional to particle size. This charge is then transferred to a collector where it is measured by a highly sensitive electrometer, generating a signal in direct proportion to the quantity of analyte present [20].

Applications of the Corona CAD in the literature are varied and concern analysis of statins [21], xanthophylls [22], sugars [23], composition of structural carbohydrates [24], pharmaceutical formulations [25-28], amino acids [29] or saikosaponins [16]. Although an increasing number of papers about the CAD are being published in the literature, food additives analysis applications of the CAD are still rare [14].

Therefore, the purpose of this work was to propose a new methodology for simultaneous determination of aspartame, acesulfame-K, saccharin, citric acid and sodium benzoate by Corona CAD and ultraviolet-diode array detector (UV-DAD) and ESI-TOF-MS in various diet supplements and non-alcoholic beverages. As the use of food additives is limited by specific regulations, there is a constant need to evaluate their role in pharmaceuticals and food products. With respect to consumer health, it is extremely important to control their amounts in food products and this new methodology could be of great use to foods and pharmaceutical preparations analysis control.

\section{Experimental}

\section{Instrumentation}

All compounds, i.e. aspartame, acesulfame-K, saccharin, citric acid and sodium benzoate were separated by a chromatographic HPLC Ultimate 3000 Series system (Dionex, Germering, Germany) that composed of a quaternary pump, degasser, an automated autosampler and a thermostatic column compartment. Detection was carried out with a Corona CAD instrument (ESA, Chelmsford, MA, USA) that was placed in series after the UV/DAD detector (Ultimate 3000, Dionex). Data collection and processing were achieved by Chromeleon 6.8 software (Dionex). Nitrogen gas flow rate was regulated automatically at 35 psi and monitored by the CAD device. It was supplied by nitrogen generator Sirocco-5 (Schmidlin-DBS, Switzerland). Response range of Corona CAD was set to $20 \mathrm{pA}$ full scale, and medium filter was applied.

Mass spectrometer MicrOTOF-QII from Bruker Daltonik (Bremen, Germany) was used to obtain the mass spectra for peak identifications. The following settings were used: electrospray ionisation (ESI) in the positive ion mode. Dry gas flow rate was set to $9.01 \mathrm{~min}^{-1}$ and the dry heater at $190{ }^{\circ} \mathrm{C}$. The capillary voltage was set to $4500 \mathrm{~V}$ and end plate offset to $-500 \mathrm{~V}$. MS data were recorded in the full scan mode (from 50 to $800 \mathrm{~m} / \mathrm{z}$ ).

In order to obtain optimal chromatographic separation and the best peak shape, water-methanol mobile phases containing TFA were evaluated. For both, HPLC-UV and HPLC-CAD, methods, the best response was obtained with a Thermo Hypersil (Thermo Fisher Scientific, Waltham, MA, USA) C18 column packed with $5 \mu \mathrm{m}$ shell particles $(150 \times 4.6 \mathrm{~mm})$. The column was equilibrated at 30 ${ }^{\circ} \mathrm{C}$ at the flow rate $0.8 \mathrm{~mL} / \mathrm{min}$. The volume of injection was $20 \mu \mathrm{L}$. Particular chromatographic conditions are presented in Table 1 . The UV-VIS diode array detector enables simultaneous determination of investigated compound at different wavelengths. UV signals at $210 \mathrm{~nm}$ (aspartame and saccharin) and $220 \mathrm{~nm}$ (acesulfame- $\mathrm{K}$ and sodium benzoate) were recorded on the DAD detector using an acquisition rate of 10 points per second (pps, Hz). Gradient mobile phase methanol-water with $0.05 \%$ TFA at a flow rate of $0.80 \mathrm{~mL} / \mathrm{min}$ was applied.

Statistical analyses, i.e. linear regression and tests for intercept, slope, intra- and inter-day repeatability were performed by the Statistica for Windows (version 10, Statsoft, 1984-2011, Cracow, Poland) software package. 
Table 1 Chromatographic conditions applied in the analysis

\begin{tabular}{|c|c|}
\hline Column & $\mathrm{C} 18(150 \times 4.6 \mathrm{~mm} ; 5.0 \mu \mathrm{m})$ \\
\hline Mobile phase & $\begin{array}{l}\text { Methanol/water } 1-40 \% \text { gradient } \\
\text { flow } 1 \% \text { A for } 9 \text { min, } 1-40 \% 9-20 \mathrm{~min} \text {, } \\
40 \% 20-32 \mathrm{~min}, 40-1 \% 32-37 \mathrm{~min} \text {, } \\
1 \% 37-40 \mathrm{~min}\end{array}$ \\
\hline Flow rate & $0.8 \mathrm{~mL} / \mathrm{min}$ \\
\hline Injection volume & $20 \mu 1$ \\
\hline Temperature & $30^{\circ} \mathrm{C}$ \\
\hline Detector UV-DAD & $\begin{array}{l}\lambda=210 \mathrm{~nm} \text { (aspartame, } \text { saccharin }) \\
\lambda=220 \mathrm{~nm} \text { (acesulfame-K, sodium benzoate) }\end{array}$ \\
\hline $\begin{array}{l}\text { Detector } \\
\text { Corona CAD }\end{array}$ & $\begin{array}{l}\text { Range } 20 \mathrm{pA} \\
\text { Filter: medium } \\
\text { Nitrogen pressure: } 35 \mathrm{psi}\end{array}$ \\
\hline
\end{tabular}

Chemicals, reagents and standards

The chemicals used were of analytical-reagent grade: HPLC grade methanol was obtained from J.T. Baker (Malinckrodt Baker B.V., Holland) and trifluoroacetic acid from Fisher Scientific (United Kingdom). Aspartame and acesulfame-K were obtained from Supelco (Bellefonte, USA), saccharin and citric acid from Aldrich Chemistry (Steinheim, Germany) while sodium benzoate from LGC Standards (Warsaw, Poland). Standards were made up by dissolving $0.025 \mathrm{~g}$ of each individual analyte in ultra-pure water (not less than $18.2 \mathrm{M} \Omega / \mathrm{cm}$ ) from a Milli-Q system (Millipore, MA, USA) in separate $100.00-\mathrm{mL}$ volumetric flasks. These solutions were further successively diluted with ultra-pure water to obtain the required concentrations. All solutions were stored in a cool, dark place when not in use. Samples were stored for no more than 14 days.

\section{Sample preparation}

Forty commercially available products including $20 \mathrm{soft}$ drinks (caffeinated and other), 5 isotonic drinks, 7 energy drinks, 5 diet supplements and 3 tabletop sweeteners were randomly purchased in retail stores in Gdansk (Poland) and Warsaw (Poland). They were chosen to be representative of what a consumer would find in a market-based study not only in Poland but also worldwide. Each of the 120 analytical subsamples analysed was injected in triplicate. Due to the analysis conducted, it was found that 10 soft drinks and 2 energy drinks did not contain the analysed compounds. Therefore, only 84 analytical subsamples were taken into account.

All the samples of non-carbonated beverages were diluted, filtered and applied directly. Each of the carbonated drink samples was first degassed in a laboratory shaker bath during $90 \mathrm{~min}$ (in room temperature) and then diluted with ultra-pure water as required. A 1-mL volume of cola drinks was directly diluted by deionized water to a $25-\mathrm{mL}$ volumetric flask, whereas other products were diluted tenfold before HPLC analysis. An accurately weighed amount of $1.0000 \mathrm{~g}$ of finely ground and homogenised diet supplements and tabletop sweeteners, which were in solid form, was dissolved in ultra-pure water in $100-\mathrm{mL}$ volumetric flask. Similarly to beverages, solid samples solutions were also diluted tenfold before HPLC analysis. Final solutions of the samples, which were prepared ex tempore, were filtered through $0.45 \mu \mathrm{m}$ filters prior to analysis.

\section{Results and discussion}

Validation of the method

The developed analysis method was validated, and the results of validation study are summarised in Table 2 . Corona CAD is a mass-dependent detector so it detects semivolatile compounds regardless of their spectral or physicochemical properties. It is known that CAD response is not directly linear over a broad concentration range, and good linearity is usually obtained only in a logarithmic coordinate system $[15,29,30]$. However, there are some studies in which it was reported that Corona CAD detector response was linear over a limited range [14, 20, 27]. This allows applying a linear calibration function in a limited concentration range.

A linearity experiment was performed by preparing mixed standard solutions of citric acid, acesulfame$\mathrm{K}$, saccharin, aspartame and sodium benzoate which were analysed under optimum conditions mentioned in Table 1. The external calibration curves were constructed by six repeated injections of these standard solutions at 8 concentration levels in the range of $1.5-50 \mu \mathrm{g} / \mathrm{mL}$ for sodium benzoate, acesulfame-K, aspartame and saccharin or at 5 calibration points in the range of $10-50 \mu \mathrm{g} /$ $\mathrm{mL}$ for citric acid (Table 2). The calibration curves were obtained by plotting concentration $(\mu \mathrm{g} / \mathrm{mL})$ against peak area. Responses obtained in the examined range (Table 2) were expressed by a linear equation $y=a x+b$ with good $r^{2}$ determination coefficient values. The linearity of the calibration graphs was highly acceptable as proved basing on a high correlation coefficient $(r \geq 0.999)$. The calibration curves were linear in the defined range for all the compounds analysed except for citric acid which linearity was obtained in a logarithmic coordinate system (Table 2). Therefore, it can be concluded that the method was appropriate for quantitative purposes for both UV and CAD detection approach. The peak elution order was confirmed according to the retention time of the standards and HPLC-ESI-TOF-MS spectra. 
Table 2 Validation data of the analytical methodology

\begin{tabular}{|c|c|c|c|c|c|c|c|c|c|}
\hline \multirow{2}{*}{$\begin{array}{l}\text { Additive/ } \\
\text { Detector }\end{array}$} & \multicolumn{3}{|l|}{ Linearity } & \multirow{2}{*}{$\begin{array}{l}\text { Fortification } \\
\text { levels } \\
(\mu \mathrm{g} / \mathrm{mL})\end{array}$} & \multirow{2}{*}{$\begin{array}{l}\text { Recovery } \\
(\%)\end{array}$} & \multirow{2}{*}{$\begin{array}{l}\text { RSD } \\
\text { intra-day } \\
(\%)\end{array}$} & \multirow{2}{*}{$\begin{array}{l}\text { RSD } \\
\text { inter-day } \\
(\%)\end{array}$} & \multirow{2}{*}{$\begin{array}{l}\text { LOD } \\
(\mu \mathrm{g} / \mathrm{mL})\end{array}$} & \multirow{2}{*}{$\begin{array}{l}\text { LOQ } \\
(\mu \mathrm{g} / \mathrm{mL})\end{array}$} \\
\hline & $\begin{array}{l}\text { Calibration } \\
\text { curve range } \\
(\mu \mathrm{g} / \mathrm{mL})\end{array}$ & $r^{2}$ & Calibration curve & & & & & & \\
\hline \multirow{4}{*}{$\begin{array}{l}\text { Aspartame/ } \\
\text { UV-DAD }\end{array}$} & \multirow[t]{4}{*}{$1.5-50$} & \multirow[t]{4}{*}{0.9999} & \multirow[t]{4}{*}{$y=0.510 x+0.202$} & 5 & 99.3 & 1.55 & 2.22 & \multirow[t]{4}{*}{0.08} & \multirow[t]{4}{*}{0.23} \\
\hline & & & & 10 & 98.1 & 0.76 & 2.60 & & \\
\hline & & & & 20 & 99.5 & 1.20 & 2.25 & & \\
\hline & & & & 40 & 98.8 & 0.92 & 2.62 & & \\
\hline \multirow{4}{*}{$\begin{array}{l}\text { Aspartame/ } \\
\text { Corona CAD }\end{array}$} & \multirow{4}{*}{$1.5-50$} & \multirow[t]{4}{*}{0.9997} & \multirow[t]{4}{*}{$y=2.520 x+0.423$} & 5 & 100.3 & 0.47 & 1.80 & \multirow[t]{4}{*}{0.06} & \multirow[t]{4}{*}{0.19} \\
\hline & & & & 10 & 99.6 & 0.85 & 2.18 & & \\
\hline & & & & 20 & 101 & 0.57 & 0.67 & & \\
\hline & & & & 40 & 99.8 & 0.45 & 0.53 & & \\
\hline \multirow{4}{*}{$\begin{array}{l}\text { Acesulfame- } \\
\text { K/UV-DAD }\end{array}$} & \multirow{4}{*}{$1.5-50$} & \multirow[t]{4}{*}{0.9999} & \multirow[t]{4}{*}{$y=0.979 x+0.172$} & 5 & 99.6 & 1.34 & 2.98 & \multirow[t]{4}{*}{0.20} & \multirow[t]{4}{*}{0.61} \\
\hline & & & & 10 & 98.7 & 0.94 & 1.93 & & \\
\hline & & & & 20 & 99.5 & 0.33 & 2.73 & & \\
\hline & & & & 40 & 99.6 & 0.31 & 1.36 & & \\
\hline \multirow{4}{*}{$\begin{array}{l}\text { Saccharin/ } \\
\text { UV-DAD }\end{array}$} & \multirow[t]{4}{*}{$1.5-50$} & \multirow[t]{4}{*}{0.9995} & $y=0.417 x+0.470$ & 5 & 99.3 & 0.24 & 1.72 & 0.28 & 0.84 \\
\hline & & & & 10 & 100.1 & 0.11 & 1.82 & & \\
\hline & & & & 20 & 98.7 & 1.03 & 1.21 & & \\
\hline & & & & 40 & 100 & 0.75 & 1.19 & & \\
\hline Saccharin/ & $1.5-50$ & 0.9995 & $y=2.118 x+0.038$ & 5 & 99.4 & 0.86 & 2.96 & 0.21 & 0.64 \\
\hline Corona & & & & 10 & 99.1 & 1.34 & 2.54 & & \\
\hline & & & & 20 & 101 & 0.46 & 2.12 & & \\
\hline & & & & 40 & 98.7 & 0.56 & 1.94 & & \\
\hline Citric acid/ & $10-50$ & 0.9992 & $\log y=\log 1.336 x-0.831$ & 5 & 100.2 & 1.63 & 2.75 & 2.70 & 8.09 \\
\hline Corona & & & & 10 & 100 & 0.62 & 1.61 & & \\
\hline & & & & 20 & 99.3 & 1.73 & 2.63 & & \\
\hline & & & & 40 & 98.7 & 0.24 & 0.85 & & \\
\hline Sodium & $0.50-50$ & 0.9997 & $y=1.155 x+0.368$ & 5 & 98.6 & 0.68 & 2.17 & 0.42 & 1.27 \\
\hline benzoate/ & & & & 10 & 99.8 & 0.66 & 1.85 & & \\
\hline UV-DAD & & & & 20 & 98.6 & 0.70 & 2.79 & & \\
\hline & & & & 40 & 101 & 0.23 & 1.26 & & \\
\hline
\end{tabular}

The estimation of the detection and quantitation limits was done based on the calibration curve, using $3 \mathrm{SD} / \mathrm{b}$ and $10 \mathrm{SD} / \mathrm{b}$ ( $\mathrm{SD}$ is the standard deviation of the curve, and $\mathrm{b}$ is the slope of the curve) (Table 2).

Repeatability was assessed using four concentrations covering the specified range for the procedure. The precision was calculated from three consecutive injections for each concentration, and the observed RSD ranged from 0.11 to $1.73 \%$ (Table 2). The intermediate precision was determined by analysing the same samples during two consequent days.

Recovery study was conducted through standard additions method, i.e. by spiking a soft drink with known amounts of aspartame, acesulfame-K, saccharin, citric acid and sodium benzoate (Table 2). The accuracy of the recovery for each of the compounds mentioned above added to a soft drink was evaluated at four levels, i.e. standard concentrations values were as follows: 5, 10, 20 and $40 \mu \mathrm{g} / \mathrm{ml}$. The analytical results obtained in each instance for nine replicates of each concentration for the analysed fortified samples were highly satisfying; the recoveries for the analytes studied ranged between 98.1 and $101 \%$ (Table 2).

Quantitative analysis of the food additives in the commercial food products

In order to verify the applicability of the proposed method, commercial food products were examined. The identification and determination of aspartame, acesulfame-K, saccharin, sodium benzoate and citric acid were done in diet supplements, table sweeteners and non-alcoholic beverages by means of HPLC coupled with Corona CAD, UVDAD and ESI-TOF-MS. The advantages of HPLC-MS 


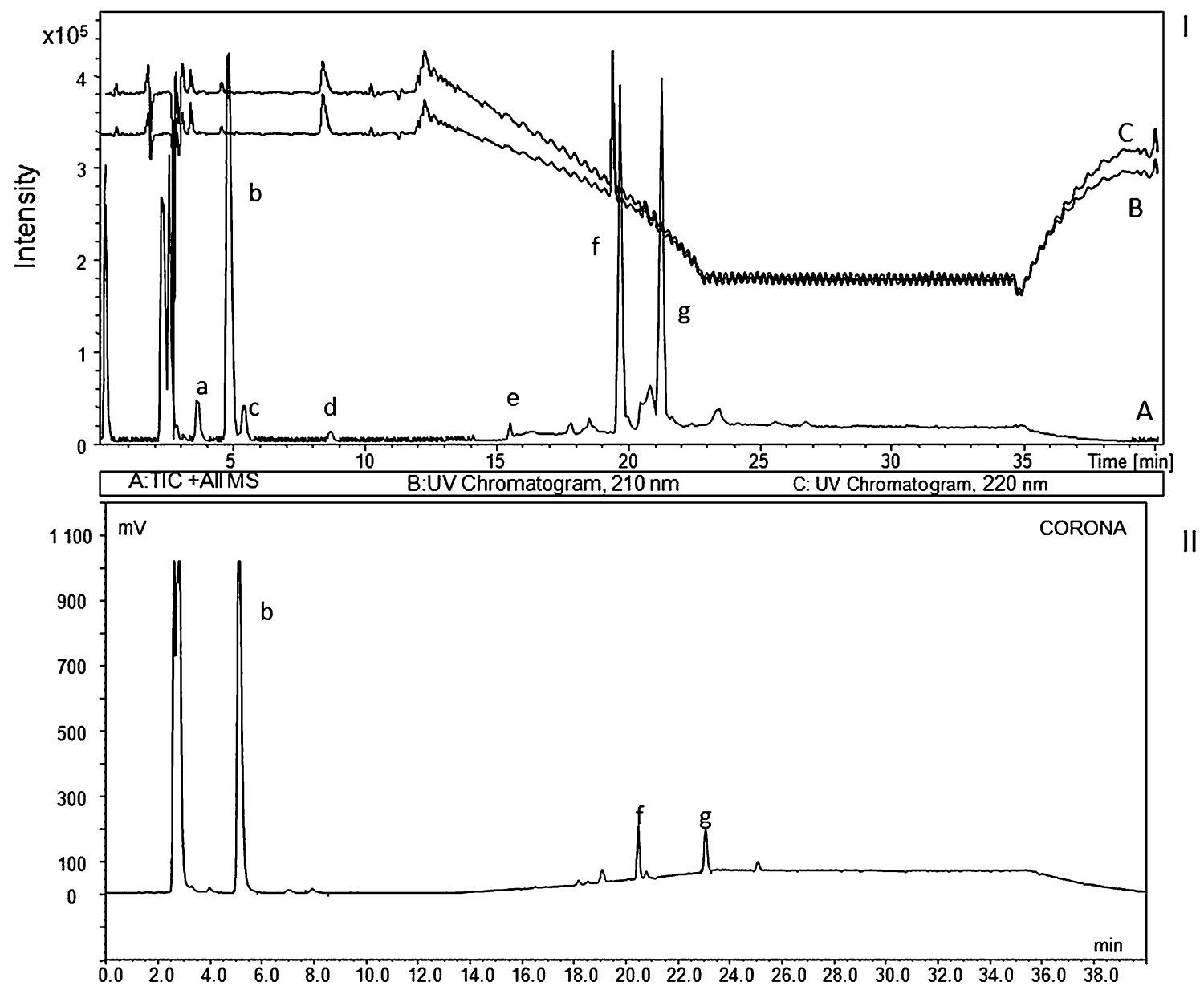

Fig. 1 Chromatograms obtained from: I HPLC-TOF-MS, II Corona $\mathrm{CAD}$, analyses of the exemplary energy drink. Seven compounds were identified by HPLC-TOF-MS, i.e. $a$ nicotinamide (m/z 123.16),

include its high specificity, sensitivity and ability to identify the unknowns even in small amounts. Therefore, the use of TOF-MS allowed on accurate mass measurements of molecules present in our samples and confirmation of the presence not only of aspartame, acesulfame-K, saccharin, sodium benzoate and citric acid but also caffeine and group B vitamins (Fig. 1). The calibration curves were obtained by plotting concentration $(\mu \mathrm{g} / \mathrm{mL})$ against peak area.

The analytical methodology revealed good linearity, sensitivity, accuracy and precision (Table 2). All samples were analysed according to the experimental conditions (Table 1). The results concerning aspartame and saccharin content in diet supplements, energy drinks, isotonic drinks, soft drinks and table sweeteners are summarised in Table 3, whereas acesulfame-K, sodium benzoate and citric acid data in Table 4. Their concentrations given for whole groups of products are characterised by arithmetic mean value, the corresponding standard deviation (SD) and ranges for wet weight basis. $b$ citric acid (m/z 193.12), $c$ pyridoxine (m/z 170.16), $d$ acesulfame $(\mathrm{m} / \mathrm{z} 164.00), e$ pantothenic acid $(\mathrm{m} / \mathrm{z} 220.21), f$ caffeine $(\mathrm{m} / \mathrm{z}$ 159.09), $g$ aspartame (m/z 295.29)

The results obtained for aspartame and saccharin (Table 3) reveal a good agreement between those determined by UV-DAD and Corona CAD, which indicates that Corona CAD would be a beneficial alternative to UV-DAD for the separation and determination of these substances. However, some abnormal characteristics of CAD were noticed for the detection of acesulfame-K and sodium benzoate. While aspartame and saccharin could be detected not only by UV-DAD but also CAD as expected, acesulfame$\mathrm{K}$ and sodium benzoate did not give a reasonable signal by CAD and could be only registered with UV-DAD detector (Figs. 2, 3). It is difficult to explain the lack of detectability of these two compounds, since they are supposed to be of low volatility [31]. Similar abnormality was observed by Stojanovic et al. [32] who could not explain the complete lack of detectability of CAD for benzoic and thiosalicylic acids. However, it was also stated that benzoic acid can be volatile with steam [32] so it might be also explanation for lack of sodium benzoate peak in CAD system. Therefore, it should be taken into account that not every compound can 
Table 3 Aspartame and saccharin concentrations $[\mathrm{mg} / 100 \mathrm{~mL}$ or $\mathrm{mg} / \mathrm{g}]$ in the analysed products

\begin{tabular}{|c|c|c|c|c|c|}
\hline \multirow[t]{2}{*}{ Product } & \multirow[t]{2}{*}{$n$} & \multicolumn{2}{|c|}{ Aspartame $(\mathrm{mg} / 100 \mathrm{~mL}$ or $\mathrm{mg} / \mathrm{g} *)$} & \multicolumn{2}{|c|}{ Saccharin $(\mathrm{mg} / 100 \mathrm{~mL})$} \\
\hline & & UV-DAD & Corona CAD & UV-DAD & $\begin{array}{l}\text { Corona } \\
\text { CAD }\end{array}$ \\
\hline Diet supplements* & 45 & $4.14 \pm 0.40$ & $3.33 \pm 0.35$ & ND & ND \\
\hline Energy drinks & 45 & $7.37 \pm 3.44$ & $6.19 \pm 3.16$ & ND & ND \\
\hline Isotonic drinks & 45 & $4.25 \pm 2.77$ & $4.13 \pm 2.53$ & ND & ND \\
\hline Soft drinks & 90 & $6.13 \pm 5.19$ & $5.50 \pm 4.43$ & $6.74 \pm 0.20$ & $6.38 \pm 0.06$ \\
\hline Table sweeteners* & 27 & $243 \pm 172$ & $235 \pm 178$ & ND & ND \\
\hline
\end{tabular}

$n$ number of analytical subsamples multiplied by number of injections (3)

$N D$ not detected

asterisks indicate material in form of tablets, concentration expressed as $\mathrm{mg} / \mathrm{g}$

Table 4 Acesulfame-K, sodium benzoate and citric acid concentrations ( $\mathrm{mg} / 100 \mathrm{~mL} \mathrm{or} \mathrm{mg} / \mathrm{g})$ in the analysed products

\begin{tabular}{lllll}
\hline Product & $n$ & $\begin{array}{l}\text { Acesulfame-K }(\mathrm{mg} / 100 \mathrm{~mL} \text { or } \\
\mathrm{mg} / \mathrm{g} *\end{array}$ & $\begin{array}{l}\text { Sodium benzoate }(\mathrm{mg} / 100 \mathrm{~mL} \text { or } \\
\mathrm{mg} / \mathrm{g} *) \\
\text { UV-DAD }\end{array}$ & $\begin{array}{l}\text { Citric acid }(\mathrm{mg} / 100 \\
\mathrm{mL} \text { or } \mathrm{mg} / \mathrm{g} *) \\
\text { Corona CAD }\end{array}$ \\
\hline Diet supplements* & 45 & $4.43 \pm 0.66$ & $\mathrm{ND}$ & $347 \pm 212$ \\
Energy drinks & 45 & $11.0 \pm 7.72$ & $7.22 \pm 10.5$ & $319 \pm 179$ \\
Isotonic drinks & 45 & $4.30 \pm 0.23$ & $14.2 \pm 11.0$ & $196 \pm 53.2$ \\
Soft drinks & 90 & $8.94 \pm 6.62$ & $9.05 \pm 4.48$ & $111 \pm 39.4$ \\
Table sweeteners* & 27 & ND & ND & ND \\
\hline
\end{tabular}

$n$ number of analytical subsamples multiplied by number of injections (3)

$N D$ not detected

asterisks indicate material in form of tablets, concentration expressed as $\mathrm{mg} / \mathrm{g}$

be detected by CAD even if it is in first instance assumed to be of low volatility [32]. The reversed situation was observed in the case of citric acid which is most commonly assayed by indirect UV method due to lack of absorption of UV light in the range typically used in chromatography (>200 nm) [33]. Since Corona CAD measures a physical property of analyte irrespectively of presence of chromophores, so citric acid peak could be registered in our study (Figs. 2, 3) and application of TOF-MS, allowed on confirmation of citric acid presence in the analysed samples (Fig. 1).

The synergism among sweeteners is a very useful property affecting sweetness and taste of the final product [34]. In case of saccharin, it is strongly recommended to use synergistic mixture of sweeteners as it influences positively on final taste at the same time decreasing the cost of the product. Although acesulfame-K can be used as an intense sweetener by itself, its blends with many other sweet tasting substances show better sweetness properties than the single substances. Blends of acesulfame-K and aspartame show a high quantitative synergism of up to 40 or even $50 \%$ [34]. The results obtained for table sweeteners confirm this synergistic effect, which allowed on a significant reduction in the amount of one of them. The table

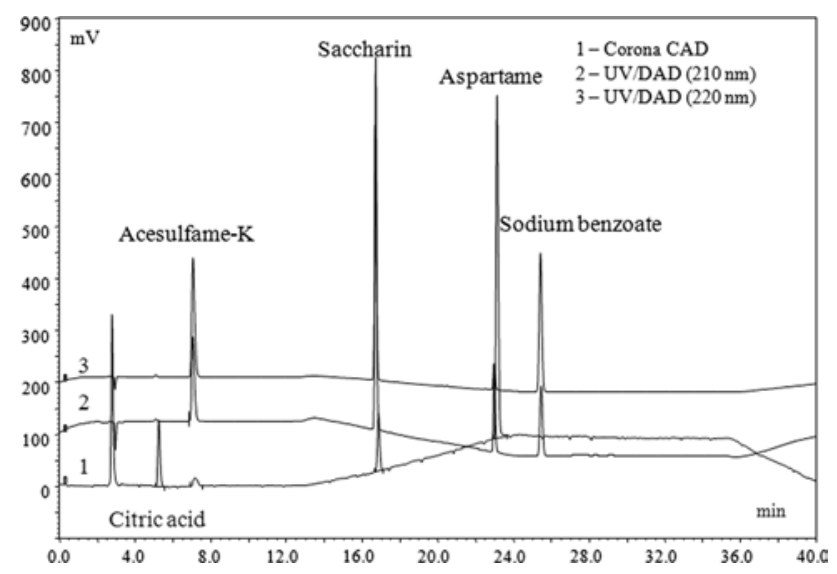

Fig. 2 Chromatograms of a standard sample containing $40 \mu \mathrm{g} / \mathrm{mL}$ of citric acid $\left(t_{\mathrm{R}} 5.26 \mathrm{~min}\right.$-Corona CAD $)$, acesulfame-K $\left(t_{\mathrm{R}} 7.06 \mathrm{~min}-\right.$ UV-DAD), saccharin ( $t_{\mathrm{R}} 16.7$ min-UV-DAD; 16.8-Corona CAD), aspartame $\left(t_{\mathrm{R}} 23.01 \mathrm{~min}-\mathrm{UV}-\mathrm{DAD} ; 23.1\right.$-Corona CAD) and sodium benzoate $\left(t_{\mathrm{R}} 25.5 \mathrm{~min}-\mathrm{UV}-\mathrm{DAD}\right) .1$. Corona CAD 2. UV-DAD (210 nm) 3. UV-DAD (220 nm). Thermo Hypersil GoldC18 column packed with $5 \mu \mathrm{m}$ shell particles $(150 \times 4.6 \mathrm{~mm})$; mobile phase: methanol-water with $0.05 \%$ TFA gradient mobile phase; flow rate of $0.80 \mathrm{~mL} / \mathrm{min}$

sweetener which consisted only of aspartame contained the highest concentration of this sweetener, i.e. $353 \mathrm{mg} / \mathrm{g}$, whereas when there were aspartame and sodium saccharin 


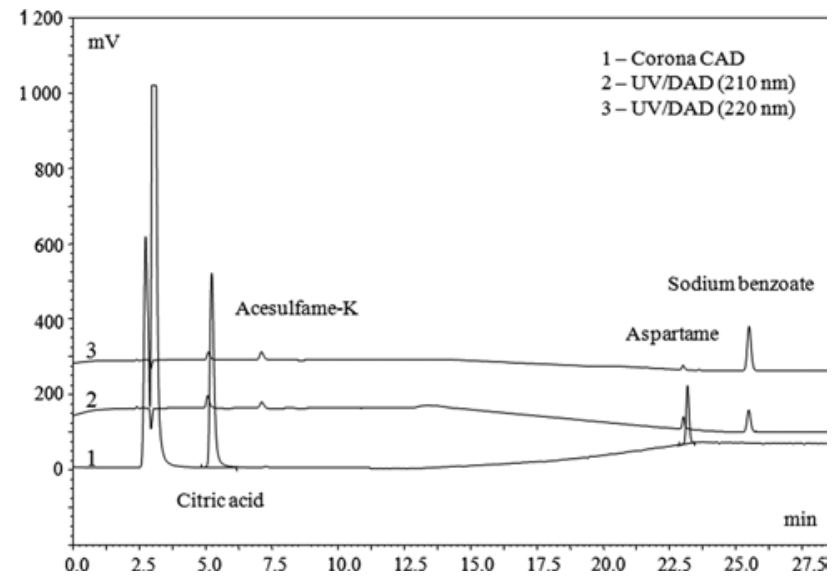

Fig. 3 Chromatograms of a soft drink sample containing citric acid $\left(t_{\mathrm{R}} 5.26 \mathrm{~min}\right.$-Corona CAD), acesulfame-K $\left(t_{\mathrm{R}} 7.06\right.$ min- $\mathrm{UV}-$ DAD), aspartame $\left(t_{\mathrm{R}} 23.01 \mathrm{~min}-\mathrm{UV}-\mathrm{DAD} ; 23.1\right.$-Corona CAD) and sodium benzoate $\left(t_{\mathrm{R}} 25.5 \mathrm{~min}-\mathrm{UV}-\mathrm{DAD}\right)$. 1. Corona CAD 2. UV-DAD $(210 \mathrm{~nm}) 3$. UV-DAD $(220 \mathrm{~nm})$. Thermo Hypersil GoldC18 column packed with $5 \mu \mathrm{m}$ shell particles $(150 \times 4.6 \mathrm{~mm})$; mobile phase: methanol-water with $0.05 \%$ TFA gradient mobile phase; flow rate of $0.80 \mathrm{~mL} / \mathrm{min}$

present aspartame amount decreased to $30.3 \mathrm{mg} / \mathrm{g}$. In several soft drinks analysed, there were blends of aspartame and acesulfame-K or saccharin then in such combinations aspartame or acesulfame-K was used in smaller amounts. Aspartame concentration in each of the analysed diet supplements was comparable (3.86-4.59 mg/g by UV-DAD or $2.94-3.61 \mathrm{mg} / \mathrm{g}$ by CAD) but varied significantly in other products (beverages and table sweeteners), whereas saccharin concentration in soft drinks did not differ significantly $(6.56-6.97 \mathrm{mg} / 100 \mathrm{~mL}$ by UV-DAD or $6.35-$ $6.44 \mathrm{mg} / 100 \mathrm{~mL}$ by CAD) (Table 3).

Citric acid, which is widely used as flavouring and stabilising agent in pharmaceuticals and food products, was the most abundant additive in all the samples analysed except for table sweeteners (Table 5). It is understandable as it was mentioned as the first component of diet supplements formulations on the label. The lowest content of citric acid as well as sodium benzoate was determined in one of caffeinated soft drinks $(13.0 \mathrm{mg} / 100 \mathrm{~mL}$ and $5.50 \mathrm{mg} / 100 \mathrm{~mL}$, respectively). It might have been caused by the fact that this product also contained orthophosphoric acid which is also used as acidity regulator, similarly to citric acid. Sodium benzoate was determined in all three groups of drinks, i.e. energy, isotonic and soft ones and its concentration varied significantly (Table 4). These differences might result from usage of only sodium benzoate or blends with other preservatives such as potassium sorbate.

The analysed products were also estimated in view of the maximum permitted usage levels (MPUL) for aspartame, acesulfame-K, saccharin and sodium benzoate, and the results as well as MPUL values according to Polish law [35] and Codex Alimentarius [36] are presented in Table 5.

The primary objective of establishing maximum use levels for food additives in various food groups was to ensure that the intake of an additive from all its sources does not exceed its adequate daily intake (ADI). ADI is a measure of the amount of a specific substance that can be ingested on a daily basis over a lifetime without an appreciable health risk [36]. The ADI values for aspartame, acesulfame-K, saccharin and sodium benzoate [37] and percentage of their realisation through consumption of the analysed products are presented in Table 5. However, citric acid, according to WHO, is considered safe to use so no specific ADI has been evaluated, and there is no limitation of its use in production except for the good manufacturing practices [31, 38]. As it can be observed in Table 5, the percentage of ADI realisation is lower than $10 \%$, and the highest value was recorded for sodium benzoate in isotonic drinks $(10.1 \%)$. Although the exposure to these food additives through consumption of analysed products is small, it must be remembered that they are present in a great variety of products we consume daily; therefore, it is crucial to monitor their levels in food products as well as in pharmaceuticals. According to the Report from the Commission on Dietary Food Additive Intake in the European Union [39], aspartame and saccharin intakes among populations did not exceed values calculated based on food consumption and maximum permitted usage of additive. However, range of estimated intake of sodium benzoate among adults and whole populations varied between 6 and $84 \%$ ADI [39].

\section{Conclusions}

There are hundreds of food additives and thousands of ways to use them for producing food and drinks. That is why monitoring of food additives consumption as well as their determination in fast growing number of food products should be carried out to ensure that their use does not exceed the acceptable daily intake (ADI) set for additives for health reasons. The newly developed method is characterised by high sensitivity and selectivity. HPLC system coupled with Corona CAD and UV-DAD detectors with gradient elution enabled accurate determination of aspartame, acesulfame-K, saccharin, citric acid and sodium benzoate in various types of food products in a single run. The obtained results for diet supplements, energy, isotonic and soft drinks as well as tabletop sweeteners indicate that Corona CAD would be a beneficial alternative to UV-DAD for the separation and determination of aspartame, saccharin and citric acid in routine foods analyses. 
Table 5 Realisation of adequate daily intake (ADI) [\%] and maximum permitted usage levels (MPUL) (\%) for aspartame, acesulfame-K, saccharin and sodium benzoate

\begin{tabular}{|c|c|c|c|c|}
\hline Name & ADI & Realisation of $\mathrm{ADI}^{\mathrm{b}}(\%)$ & MPUL $^{\mathrm{c}}$ & Realisation of MPUL ${ }^{\mathrm{d}}(\%)$ \\
\hline \multicolumn{5}{|l|}{ Aspartame } \\
\hline Diet supplements (Corona CAD) & $\begin{array}{r}40 \mathrm{mg} / \mathrm{kg} \text { b.w./day } \\
(2,800 \mathrm{mg} / \text { day })^{\mathrm{a}}\end{array}$ & 0.12 & $\begin{array}{l}2,000 \mathrm{mg} / \mathrm{kg} \\
5,500 \mathrm{mg} / \mathrm{kg}^{*}\end{array}$ & 166 \\
\hline Diet supplements (UV-DAD) & & 0.15 & & 207 \\
\hline Energy drinks (Corona CAD) & & 0.55 & $\begin{array}{l}600 \mathrm{mg} / \mathrm{L} \\
600 \mathrm{mg} / \mathrm{kg}^{*}\end{array}$ & 10.3 \\
\hline Energy drinks (UV-DAD) & & 0.66 & & 3.07 \\
\hline Isotonic drinks (Corona CAD) & & 0.37 & & 6.87 \\
\hline Isotonic drinks (UV-DAD) & & 0.38 & & 7.07 \\
\hline Soft drinks (Corona CAD) & & 0.49 & & 9.17 \\
\hline Soft drinks (UV-DAD) & & 0.55 & & 10.2 \\
\hline Table sweeteners (Corona CAD) & & 8.39 & - & - \\
\hline Table sweeteners (UV-DAD) & & 8.68 & & - \\
\hline \multicolumn{5}{|l|}{ Acesulfame-K } \\
\hline Diet supplements & $\begin{array}{l}15 \mathrm{mg} / \mathrm{kg} \text { b.w./day } \\
(1,050 \mathrm{mg} / \text { day })\end{array}$ & 0.42 & $\begin{array}{l}2,000 \mathrm{mg} / \mathrm{kg}^{*} \\
2,000 \mathrm{mg} / \mathrm{kg}^{*}\end{array}$ & 221 \\
\hline Energy drinks & & 2.62 & $\begin{array}{l}350 \mathrm{mg} / \mathrm{L} \\
600 \mathrm{mg} / \mathrm{kg}^{*}\end{array}$ & 31.4 \\
\hline Isotonic drinks & & 1.02 & & 12.3 \\
\hline Soft drinks & & 2.13 & & 25.5 \\
\hline \multicolumn{5}{|l|}{ Saccharin } \\
\hline Soft drinks (Corona CAD) & $\begin{array}{l}5 \mathrm{mg} / \mathrm{kg} \text { b.w./day } \\
(350 \mathrm{mg} / \text { day })^{\mathrm{a}}\end{array}$ & 4.83 & $\begin{array}{l}80 \mathrm{mg} / \mathrm{L} \\
300 \mathrm{mg} / \mathrm{kg}^{*}\end{array}$ & 84.5 \\
\hline Soft drinks (UV-DAD) & & 4.56 & & 79.8 \\
\hline \multicolumn{5}{|l|}{ Sodium benzoate } \\
\hline Energy drinks & $\begin{array}{l}5 \mathrm{mg} / \mathrm{kg} \text { b.w./day } \\
(350 \mathrm{mg} / \mathrm{day})^{\mathrm{a}}\end{array}$ & 5.17 & $\begin{array}{l}150 \mathrm{mg} / \mathrm{L} \\
600 \mathrm{mg} / \mathrm{kg}^{*}\end{array}$ & 48.3 \\
\hline Isotonic drinks & & 10.1 & & 94.7 \\
\hline Soft drinks & & 6.46 & & 60.3 \\
\hline
\end{tabular}

a ADI recalculated for a person of $70 \mathrm{~kg}$

${ }^{\mathrm{b}}$ Estimated for consumption of $1 \mathrm{~g}$ of diet supplements or table sweeteners or $250 \mathrm{~mL}$ of beverages

${ }^{c}$ MPUL-maximum permitted usage level

d Realisation of MPUL set by Polish law [35]

* MPUL_maximum permitted level according to FAO/WHO [36]

\section{Conflict of interest None.}

Compliance with Ethics Requirements This article does not contain any studies with human or animal subjects.

Open Access This article is distributed under the terms of the Creative Commons Attribution License which permits any use, distribution, and reproduction in any medium, provided the original author(s) and the source are credited

\section{References}

1. Council Directive of 21 December 1988 (1988) http://www.fsai. ie/uploadedFiles/Dir89.107.pdf Accessed on 12th December 2012

2. Mortensen A (2006) Sweeteners permitted in the European Union: safety aspects. Scand J Food Nutr 50:104-116
3. Garcia-Jimenez JF, Valencia MC, Capitan-Vallvey LF (2007) Simultaneous determination of antioxidants, preservatives and sweetener additives in food and cosmetics by flow injection analysis coupled to a monolithic column. Anal Chim Acta 594:226-233

4. Ferrer I, Thurman M (2010) Analysis of sucralose and other sweeteners in water and other beverage samples by liquid chromatography/time-of-flight mass spectrometry. J Chromatogr A 1217:4127-4134

5. George V, Arora S, Wadhwa BK, Singh AK (2010) Analysis of multiple sweeteners and their degradation products in lassi by HPLC and HPTLC plates. J Food Sci Technol 47:408-417

6. Mahboubifar M, Sobhani Z, Dehghanzadeh G, Javidnia K (2011) A comparison between UV spectrophotometer and high-performance liquid chromatography method for the analysis of sodium benzoate and potassium sorbate in food products. Food Anal Method 2:150-154

7. Scotter MJ, Castle L, Roberts DPT, MacArthur R, Brereton PA, Hasnip SK, Katz N (2009) Development and single-laboratory 
validation of an HPLC method for the determination of cyclamate sweetener in foodstuffs. Food Addit Contam 26:614-622

8. Wasik A, McCourt J, Buchgraber M (2007) Simultaneous determination of nine intense sweeteners in foodstuffs by high performance liquid chromatography and evaporative light scattering detection: development and single-laboratory validation. J Chromatogr A 1157:187-196

9. Zygler A, Wasik A, Kot-Wasik A, Namieśnik J (2011) Determination of nine high-intensity sweeteners in various foods by highperformance liquid chromatography with mass spectrometric detection. Anal Bioanal Chem 400:2159-2172

10. Bergamo AB, da Silva JAF, de Jesus DP (2011) Simultaneous determination of aspartame, cyclamate, saccharin and acesulfame- $K$ in soft drinks and tabletop sweetener formulations by capillary electrophoresis with capacitively coupled contactless conductivity detection. Food Chem 124:1714-1717

11. Garcia-Jimenez JF, Valencia MC, Capitan-Vallvey LF (2006) Improved multianalyte determination of the intense sweeteners aspartame and acesulfame- $\mathrm{K}$ with a solid sensing zone implemented in an FIA scheme. Anal Lett 39:1333-1347

12. Hashemi M, Habibi A, Jahanshahi N (2011) Determination of cyclamate in artificial sweeteners and beverages using headspace single-drop microextraction and gas chromatography flame-ionisation detection. Food Chem 124:1258-1263

13. Zygler A, Wasik A, Namieśnik J (2009) Analytical methodologies for determination of artificial sweeteners in foodstuffs. Trend Anal Chem 28:1082-1102

14. Grembecka M, Szefer P (2012) Simultaneous determination of caffeine and aspartame in diet supplements and non-alcoholic beverages using liquid-chromatography coupled to Corona CAD and UV-DAD detectors. Food Anal Method 5:1010-1017

15. Dixon RW, Peterson DS (2002) Development and testing of a detection method for liquid chromatography based on aerosol charging. Anal Chem 74:2930-2937

16. Eom HY, Park S-Y, Kim MK, Suh JH, Yeom H, Min JW, Kim U, Lee J, Youm J-R, Han SB (2010) Comparison between evaporative light scattering detection and charged aerosol detection for the analysis of saikosaponins. J Chromatogr A 1217:4347-4354

17. Takahashi K, Kinugasa S, Senda M, Kimizuka K, Fukushima K, Shibata Y, Christensen J (2008) Quantitative comparison of a corona-charged aerosol detector and an evaporative light-scattering detector for the analysis of a synthetic polymer by supercritical fluid chromatography. J Chromatogr A 1193:151-155

18. Vervoort N, Daemen D, Török G (2008) Performance evaluation of evaporative light scattering detection and charged aerosol detection in reversed phase liquid chromatography. J Chromatogr A 1189:92-100

19. Vehovec T, Obreza A (2010) Review of operating principle and applications of the charged aerosol detector. J Chromatogr A 1217:1549-1556

20. Corona CAD. Polygen information sheet http://www.polygen .com.pl/presentations/corona_cad.pdf Accessed on 5th March 2011

21. Nováková L, Solichová D, Solich P (2009) Hydrophilic interaction liquid chromatography-charged aerosol detection as a straightforward solution for simultaneous analysis of ascorbic acid and dehydroascorbic acid. J Chromatogr A 1216:4574-4581

22. Ligor M, Buszewski B (2012) Study of xanthophylls concentration in spinach leaves by means of HPLC coupled with UV-VIS and Corona CAD detectors. Food Anal Method 5:388-395

23. Hutchinson JP, Remenyi T, Nesterenko P, Farrell W, Groeber E, Szucs R, Dicinoski G, Haddad PR (2012) Investigation of polar organic solvents compatible with corona charged aerosol detection and their use for the determination of sugars by hydrophilic interaction liquid chromatography. Anal Chim Acta 750:199-206

24. Godin B, Agneessens R, Gerin PA, Delcarte J (2011) Composition of structural carbohydrates in biomass: precision of a liquid chromatography method using neutral detergent extraction and a charged aerosol detector. Talanta 85:2014-2026

25. Almeling S, Ilko D, Holzgrabe U (2012) Charged aerosol detection in pharmaceutical analysis. J Pharm Biomed Anal 69:50-63

26. Jia S, Park JH, Lee J, Kwon SW (2011) Comparison of two aerosol-based detectors for the analysis of gabapentin in pharmaceutical formulations by hydrophilic interaction chromatography. Talanta 85:2301-2306

27. Błażewicz A, Fijałek Z, Warowna-Grześkiewicz M, Jadach M (2010) Determination of atracurium, cisatracurium and mivacurium with their impurities in pharmaceutical preparations by liquid chromatography with charged aerosol detection. J Chromatogr A 1217:1266-1272

28. Błażewicz A, Fijałek Z, Sarna K, Warowna-Grześkiewicz M (2010) Determination of pancuronium and its impurities by pharmaceutical preparation by LC with charged aerosol detection. Chromatographia 72:183-186

29. Holzgrabe U, Nap C-J, Almeling S (2010) Control of impurities in L-aspartic acid and L-alanine by high-performance liquid chromatography coupled with a corona charged aerosol detector. J Chromatogr A 1217:294-301

30. Sun P, Wang X, Alquier L, Maryanoff CA (2008) Determination of relative response factors of impurities in paclitaxel with high performance liquid chromatography equipped with ultraviolet and charged aerosol detectors. J Chromatogr A 1177:87-91

31. Smith J, Hong-Shum L (2011) Food additives databook. WileyBlackwell, Oxford UK

32. Stojanowic A, Lämmerhofer M, Kogelnig D, Schiesel S, Sturm M, Galanski M, Krachler R, Keppler BK, Lindner W (2008) Analysis of quaternary ammonium and phosphonium ionic liquids by reversed-phase high-performance liquid chromatography with charged aerosol detection and unified calibration. J Chromatogr A 1209:179-187

33. DeBorba BM, Rohrer JS, Bhattacharyya L (2004) Development and validation of an assay for citric acid/citrate and phosphate in pharmaceutical dosage forms using ion chromatography with suppressed conductivity detection. J Pharm Biomed Anal 36:517-524

34. Wilson R (2007) Sweeteners. Blackwell Publishing, Oxford UK

35. Ministry of Health Regulation of 22 November 2010 on the permitted food additives (2010) (Rozporządzenie Ministra Zdrowia z dnia 22 listopada 2010 r. w sprawie dozwolonych substancji dodatkowych. Dz. U. 10.232.1525) (in Polish)

36. Codex Alimentarius (1995) http://www.codexalimentarius. net/gsfaonline/docs/CXS_192e.pdf Accessed on 22nd November 2012

37. Combined Compendium of Food Additive Specifications http://www.fao.org/food/food-safety-quality/scientificadvice/jecfa/jecfa-additives/en/ Accessed on 22nd November 2012

38. EFSA. The EFSA Journal 392, 1 (2006) http://www.efsa.europa. eu/en/efsajournal/doc/392.pdf Accessed on 9th July 2011

39. Report from the Commission on Dietary Food Additive Intake in the European Union. http://ec.europa.eu/food/fs/sfp/addit_ flavor/flav15_en.pdf Accessed on 12th January 2013 